\title{
Diabetes in the young - a case of Alström syndrome with myopathy
}

\author{
${ }^{1} \mathrm{SC}$ Bronson, ${ }^{2} \mathrm{CR}$ Anand Moses, ${ }^{3} \mathrm{I}$ Periyandavar, ${ }^{3} \mathrm{P}$ Dharmarajan, ${ }^{4} \mathrm{E}$ Suresh, ${ }^{4} \mathrm{~A}$ Shanmugam, ${ }^{4} \mathrm{R}$ Vasuki, \\ ${ }^{1} \mathrm{D}$ Venkatesh, ${ }^{1} \mathrm{~J}$ Amudha \\ ${ }^{1}$ Postgraduate Resident, ${ }^{2}$ Director \& Professor, ${ }^{3}$ Professor, ${ }^{4}$ Assistant Professor, Institute of Diabetology, Madras Medical College \& Rajiv \\ Gandhi Government General Hospital, Tamil Nadu, India
}

\begin{abstract}
Alström syndrome is a rare ciliopathy affecting about I in $1,000,000$ individuals. It is characterised by cone-rod dystrophy, insulin resistance, diabetes mellitus, cardiomyopathy, renal failure and hypogonadism. Progressive multi-organ dysfunction eventually leads to death. Only about 800 patients with this disorder have been identified so far.The diagnosis of Alström syndrome is critical as it can easily be overlooked because of the many features it shares with metabolic syndrome. The gene affected in this autosomal recessive disease is ALMSI, the protein product of which is involved in intracellular trafficking and ciliary function. Alström syndrome is being studied as a model which would potentially shed light on the pathophysiology of diabetes mellitus.
\end{abstract}

In this report, we describe a patient with features of Alström syndrome and a clinical picture suggestive of a recurrent, severe, steroid responsive myopathy which, to the best of our knowledge, has not been reported so far.

KEYWORDS ALMSI, Alström, cone-rod dystrophy, diabetes, myopathy

DECLARATION OF INTERESTS No conflict of interest declared
Correspondence to SC Bronson Institute of Diabetology Madras Medical College \& Rajiv Gandhi Government General Hospital

Chennai 600003

Tamil Nadu

India

e-mail dr.s.charlesb@gmail.com

\section{INTRODUCTION}

Alström syndrome (AS), characterised by multiple system involvement, is a rare, autosomal recessive ciliopathy, affecting about $\mathrm{I}$ in $1,000,000$ individuals. The main components include cone-rod dystrophy of the retina, childhood obesity, diabetes mellitus (DM), sensorineural hearing loss, cardiomyopathy, hypogonadism, and renal and hepatic dysfunction. ${ }^{1,2}$ The expression of clinical features is variable and life expectancy is usually less than 50 years. A single gene ALMSI is identified as the gene affected in AS. ${ }^{2}$ Alström syndrome shares features with the more common metabolic syndrome, ${ }^{3}$ which may obscure the diagnosis

\section{CASE REPORT}

A I5-year-old South Indian boy presented with gradual darkening and thickening of skin since he was 6 years old; photophobia from the age of 7 and recurrent, severe, cramping muscle pain for the past two years. He suffered from one or two episodes of cramp a month, each lasting for 3-7 days with cramps persisting for minutes to hours. The cramps started in the legs; ascended to involve the trunk and upper limbs and were present even at rest. Prior to presentation he had been diagnosed with DM. He was born of a consanguineous marriage, with no perinatal complications and had normal developmental milestones. His father and late paternal grandmother suffered from DM and the boy had a younger sister. There were no other similar symptoms such as photophobia or cramps in the family.

On examination the patient's height was $164 \mathrm{~cm}$, he had a BMI of $26.8 \mathrm{~kg} / \mathrm{m}^{2}$ and blood pressure of 150//00 $\mathrm{mmHg}$. He was stocky with bilateral gynaecomastia and flat feet (Figure la). Extensive acanthosis nigricans was present in all flexures on the neck and face (Figure Ib). Secondary sexual development corresponded to Tanner stage IV. He had horizontal nystagmus - present at rest, worsened by lateral gaze; visual acuity was $6 / 60$ bilaterally; colour vision was defective but visual fields were normal. His fundi were paler than normal with attenuated arterioles. Muscle tone was normal; power was $5 / 5$, as tested in spasm-free intervals; deep tendon reflexes were present; plantar reflexes showed flexor responses and higher mental functions were normal. The liver was palpable $3 \mathrm{~cm}$ below the right costal margin.

Investigations showed the following: plasma glucose fasting: $9.2 \mathrm{mmol} / \mathrm{l}(165 \mathrm{mg} / \mathrm{dl})$, post-prandial: 15.5 $\mathrm{mmol} / \mathrm{l}$ (280 mg/dL); HbAlC - 8I mmol/mol (9.6\%). Serum glutamic acid decarboxylase autoantibody testing was negative. Fasting insulin was $59 \mathrm{mU} / \mathrm{l}$ and fasting 


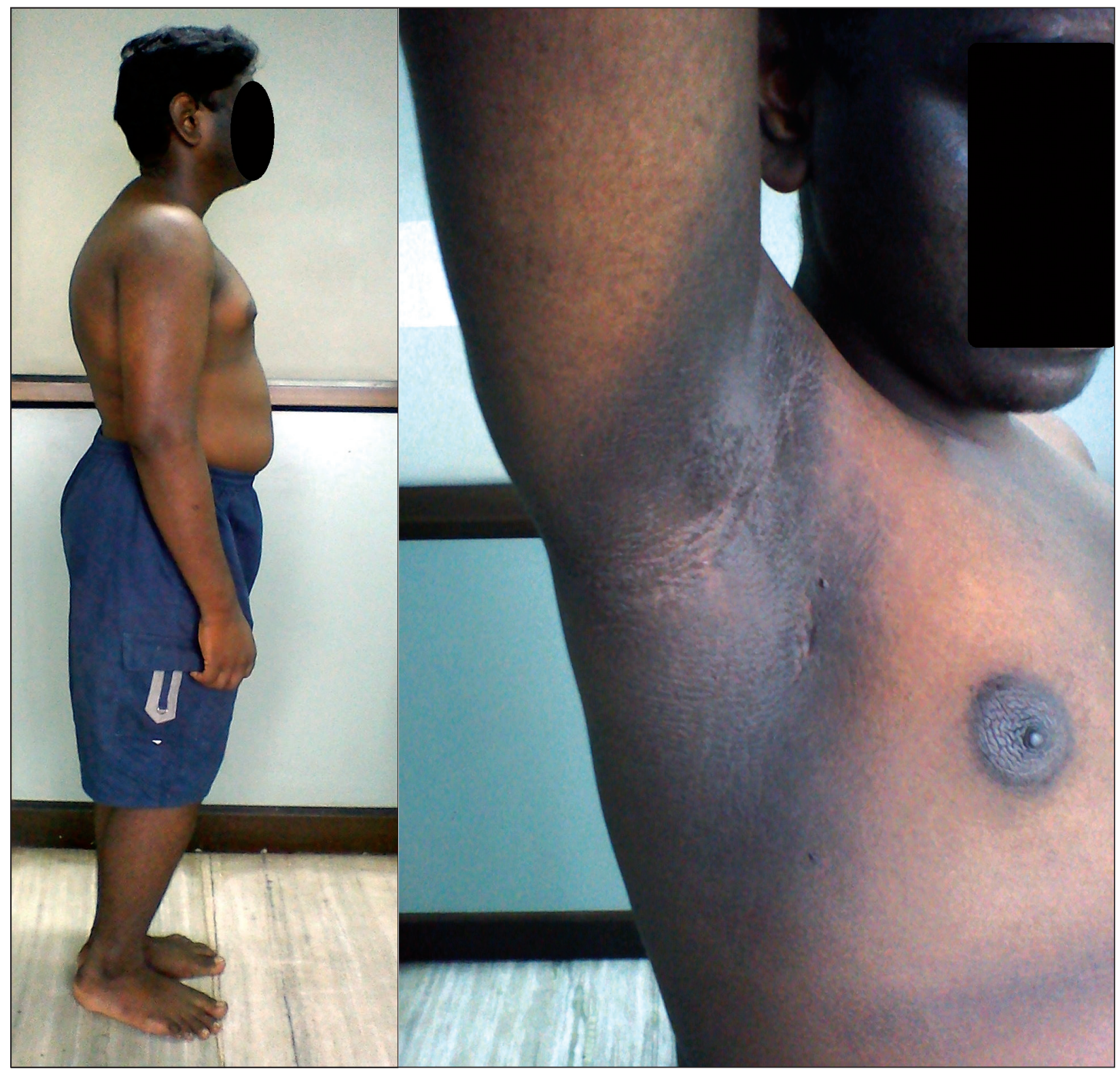

FIGURE I The patient. (Left) Note the gynaecomastia, flat feet and lordosis. (Right) Acanthosis nigricans on the face, neck, axilla and infra-mammary region

C-peptide was $13 \mathrm{ng} / \mathrm{ml}$; the patient had hyperinsulinaemia and his Homeostasis Model Assessment score of Insulin Resistance was 8.I. Serum triglycerides were elevated. Liver transaminases were elevated, albumin:globulin ratio was low, an ultrasonogram of his abdomen showed an echogenic liver consistent with hepatic steatosis, and microalbuminuria was present. Urine albumin:creatinine ratio was elevated. Serum creatine phosphokinase was elevated to 14 times the upper limit of normal. Serum lactate dehydrogenase was high. Serum calcium, phosphorous, magnesium and other electrolytes were within normal limits. The urine was negative for ketones and myoglobin. An electroretinogram revealed delayed and reduced photopic responses, suggestive of cone dystrophy. Scotopic responses were normal.
At this juncture, a possible syndromic association was considered. The boy had deep set eyes and enlarged ears. There was no alopecia or polydactyly. Audiometry showed normal hearing. However, Distortion Product Otoacoustic Emissions testing revealed defective outer hair cell functioning. Echocardiography showed normal chamber size and function and pulmonary function tests showed no abnormality. Magnetic resonance imaging of the brain showed a prominent choroid plexuses in the occipital horns of the lateral ventricles suggestive of xanthogranulomas. The sellar region was normal. Serum total and free testosterone levels were low. Other hormone levels were within normal limits. Antinuclear antibody testing was negative.

Mitochondrial disorders share some clinical features as seen in our patient. However, they also present with 
TABLE I Criteria for the diagnosis of Alström syndrome ${ }^{3}$

\begin{tabular}{|c|c|c|c|c|}
\hline $\begin{array}{l}\text { Age } \\
\text { (years) }\end{array}$ & $\begin{array}{l}\text { Criteria } \\
\text { Major }\end{array}$ & Minor & $\begin{array}{l}\text { Other supportive } \\
\text { evidence }\end{array}$ & Diagnosis \\
\hline$\leq 2^{*}$ & $\begin{array}{l}\text { - ALMSI mutation in I } \\
\text { allele and/or family } \\
\text { history of AS } \\
\text {-Vision (nystagmus, } \\
\text { photophobia) }\end{array}$ & $\begin{array}{l}\text { - Obesity } \\
\text { - DCM/CHF }\end{array}$ & $\begin{array}{l}\text { - Recurrent pulmonary } \\
\text { infections } \\
\text { - Normal digits } \\
\text { - Delayed developmental } \\
\text { milestones }\end{array}$ & $\begin{array}{l}2 \text { major criteria } \\
\text { OR } \\
\text { I major }+2 \text { minor } \\
\text { criteria }\end{array}$ \\
\hline $3-14$ & $\begin{array}{l}\text {-ALMSI mutation in I } \\
\text { allele and/or family } \\
\text { history of AS } \\
\text {-Vision (nystagmus, } \\
\text { photophobia, decreased } \\
\text { acuity, cone dystrophy by } \\
\text { ERG**) }\end{array}$ & $\begin{array}{l}\text { - Obesity and/or insulin } \\
\text { resistance } \\
\text { - (History of) DCM/CHF } \\
\text { - Hearing loss } \\
\text { - Advanced bone age } \\
\text { - Hepatic dysfunction } \\
\text { - Renal failure }\end{array}$ & $\begin{array}{l}\text { - Recurrent pulmonary } \\
\text { infections } \\
\text { - Normal digits } \\
\text { - Delayed developmental } \\
\text { milestones } \\
\text { - Hyperlipidaemia } \\
\text { - Scoliosis } \\
\text { - Flat wide feet } \\
\text { - Hypothyroidism } \\
\text { - Hypertension } \\
\text { - GH deficiency } \\
\text { - Recurrent UTI }\end{array}$ & $\begin{array}{l}2 \text { major criteria } \\
\text { OR } \\
\text { I major }+3 \text { minor } \\
\text { criteria }\end{array}$ \\
\hline$\geq 15$ & $\begin{array}{l}\text { - ALMSI mutation in I } \\
\text { allele and/or family } \\
\text { history of AS } \\
\text { - Vision (legal blindness, } \\
\text { history of nystagmus in } \\
\text { infancy/childhood, cone } \\
\text { and rod dystrophy by } \\
\text { ERG) }\end{array}$ & $\begin{array}{l}\text { - Obesity and/or insulin } \\
\text { resistance and/or T2DM } \\
\text { - (History of) DCM/CHF } \\
\text { - Hearing loss } \\
\text { - Hepatic dysfunction } \\
\text { - Renal failure } \\
\text { - Short stature } \\
\text { - Males - hypogonadism } \\
\text { - Females - irregular } \\
\text { menses and/or } \\
\text { hyperandrogenism }\end{array}$ & $\begin{array}{l}\text { - Recurrent pulmonary } \\
\text { infections } \\
\text { - Normal digits } \\
\text { - History of } \\
\text { developmental delay } \\
\text { - Hyperlipidaemia } \\
\text { - Scoliosis } \\
\text { - Flat wide feet } \\
\text { - Hypothyroidism } \\
\text { - Hypertension } \\
\text { - GH deficiency } \\
\text { - Alopecia } \\
\text { - Recurrent UTI or } \\
\text { urinary dysfunction }\end{array}$ & $\begin{array}{l}2 \text { major }+2 \text { minor } \\
\text { criteria } \\
\text { OR } \\
\text { I major }+4 \text { minor } \\
\text { criteria }\end{array}$ \\
\hline
\end{tabular}

*These diagnostic criteria should be re-evaluated when the patient becomes older; **ERG to be conducted only if the child is old enough for testing. AS, Alström syndrome; DCM/CHF, dilated cardiomyopathy/congestive heart failure; ERG, electroretinogram; GH, growth hormone; UTI, urinary tract infections; T2DM, type 2 diabetes mellitus

Reproduced from Joy et al. ${ }^{3}$ under the terms of the Creative Commons license 2.0 http://creativecommons.org/licenses/by/2.0/

features of central nervous system involvement and muscular weakness' which were not observed in this case. In considering the presence of retinal dystrophy, insulin resistance, childhood diabetes and other features, the two disorders that merited most consideration as differential diagnoses were Bardet-Biedl syndrome and AS. Based on the diagnostic guidelines (Table I), ${ }^{3}$ a diagnosis of AS was made. The absence of polydactyly and mental retardation distinguishes AS from BardetBiedl syndrome. ${ }^{1,4}$

The boy was provided with dietary counselling and advised to increase physical activity. He was started on metformin and eventually required insulin. The severe muscle cramps responded to a 10 day course of oral prednisolone. Creatine phosphokinase and lactate dehydrogenase subsided to normal with treatment. Nerve conduction study and electromyography were performed after the symptoms subsided and were found to be within normal limits. He is receiving L-carnitine supplementation at present. $\mathrm{He}$ is also being managed for the other features - photophobia, decreased vision, hypertension, proteinuria, dyslipidaemia and hypogonadism. The patient has remained symptom free with respect to muscle cramps at present. 


\section{DISCUSSION}

Alström syndrome is a rare genetic disease. Since its first description in 1959, ${ }^{5}$ only around 800 cases have been identified.'

The expression and onset of clinical features is variable. Nystagmus and photophobia develop in the majority during infancy due to cone-rod dystrophy. ${ }^{1,2}$ Patients usually become completely blind by the second decade. ${ }^{2}$ Progressive, bilateral, sensorineural hearing defects are observed in $88 \%$. Obesity (98\%) and insulin resistance (92\%) lead to glucose intolerance and DM in $68 \%$ of patients.' Liver dysfunction ranges from elevated transaminases and steatosis to cirrhosis. Other features include renal dysfunction, hypertension, dilated or restrictive cardiomyopathy, hypogonadism, hypothyroidism, hypertriglyceridaemia, chest infections, scoliosis, kyphosis and flat feet. ${ }^{1,2}$ Progressive multi-organ involvement occurs. Death usually results from cardiac, ${ }^{3,4}$ renal $^{3}$ or hepatic failure. ${ }^{2}$

A diagnosis of AS is essentially clinical, ${ }^{1,2}$ based on the age-specific criteria available. ${ }^{1,3}$

Differential diagnoses include achromatopsia, Leber's congenital amaurosis, ${ }^{1,2}$ inherited mitochondrial disorders, ' and Bardet-Biedl, Usher and Cohen syndromes. ${ }^{1.2}$ Mutations in the ALMSI gene, at chromosome 2p/3, cause AS.' ALMSI is expressed in the retinal cones and rods, liver, organ of Corti, pancreatic islets, renal tubules and hypothalamus. ${ }^{2}$ ALMSI protein is implicated in ciliary function, intracellular trafficking, ${ }^{1,2}$ and adipocyte differentiation. ${ }^{2}$ AS is therefore considered to be a ciliopathy.'

The management of AS involves a multidisciplinary approach. Specific treatment is directed at the complications. If the disease-causing mutation can be identified, carrier testing for relatives and prenatal testing are possible.'

Finally, we highlight the phenotypic variations observed in our patient. In AS, symptoms of cone dystrophy usually begin in infancy and rod function too, is impaired by five years. ${ }^{2}$ In the case we present, nystagmus and photophobia developed only when the patient was 7 years old and rod function remained normal at 15 years of age. The classic description by Alström et al. ${ }^{5}$ included neurogenic deafness. Sensorineural hearing loss is a relatively consistent feature (88\%).' In our patient however hearing was normal in audiometry, although outer hair cell functioning was defective, consistent with a ciliopathy. ALMSI mutations without phenotypic hearing loss have been reported. ${ }^{3}$ Cardiomyopathy, either of dilated or restrictive type, occurs in more than $60 \%$ of patients with AS.' No clinical or echocardiographic features of this were seen in our patient. Magnetic resonance imaging of the brain revealed bilateral xanthogranulomas of the occipital horn of the lateral ventricles. We were unable to perform genetic testing for the detection of the mutation and confirmation because of non-availability of this test in our hospital.

Even though unexplained muscle pains, leg cramps and dystonias have been described in AS,' such severe, recurrent, ascending, disabling muscle cramps involving the whole body, with markedly elevated serum creatine phosphokinase levels, suggestive of a myopathy, responding to steroid therapy, has not hitherto been described in AS to the best of our knowledge. Thus all these phenotypic peculiarities suggest a possible variant of the syndrome.

\section{CONCLUSION}

AS should always be considered in a child or adolescent presenting with insulin resistant DM with other associated features. This is especially important because of the features AS shares with metabolic syndrome which is more common. ${ }^{3}$ Prompt diagnosis will aid in the effective detection and management of complications. Alström syndrome is considered as a model for metabolic syndrome and a lot of insight has been gained on the functions of the ALMSI gene. ${ }^{2}$ It is to be hoped that these discoveries will help to elucidate the processes underlying the pathophysiology of AS, as well as other ciliopathies, obesity and DM.

\section{CONSENT}

The patient described in the case report and his father gave their informed consent for the case report to be published.

\section{ACKNOWLEDGEMENTS}

The authors thank Dr R Lakshmi Narasimhan, Professor of Neurology, Madras Medical College, and Dr I Ranjit Unnikrishnan, Consultant Diabetologist, Madras Diabetes Research Foundation, Chennai, for their valuable support. 


\section{REFERENCES}

I Marshall JD, Paisey RB, Carey C et al.Alström Syndrome. In: Pagon RA, Bird TD, Dolan CR et al., editors. GeneReviews ${ }^{\mathrm{TM}}$. Seattle, WA: University of Washington; 7 February 2003; updated 3I May 2012. http://www.ncbi.nlm.nih.gov/books/NBKI267/

2 Marshall JD, Maffei P, Collin GB et al. Alström syndrome: genetics and clinical overview. Curr Genomics 201 I; 12: 225-35. http://dx. doi.org/I0.2I74/I389202II7956779/2

3 Joy T, Cao H, Black G et al.Alstrom syndrome (OMIM 203800): a case report and literature review. Orphanet J Rare Dis 2007; 2: 49. http://dx.doi.org/I0.I I86//750-I I 72-2-49
4 Russell-Eggitt IM, Clayton PT, Coffey R et al. Alström syndrome Report of 22 cases and literature review. Ophthalmology 1998; 105 : I274-80.

5 Alström CH, Hallgren B, Nilsson LB et al. Retinal degeneration combined with obesity, diabetes mellitus and neurogenous deafness: a specific syndrome (not hitherto described) distinct from the Laurence-Moon-Bardet-Biedl syndrome: a clinical, endocrinological and genetic examination based on a large pedigree. Acta Psychiatr Neurol Scand Suppl 1959; I29: I-35.

\section{INVITATION TO SUBMIT PAPERS}

We would like to extend an invitation to all readers of The Journal of the Royal College of Physicians of Edinburgh to contribute original material, especially to the clinical section. The JRCPE is a peer-reviewed journal with a circulation of over 8,000 . It is also available open access online. Its aim is to publish a range of clinical, educational and historical material of cross-specialty interest to the College's international membership.

The JRCPE is currently indexed in Medline, Embase, Google Scholar and the Directory of Open Access Journals. The editorial team is keen to continue to improve both the quality of content and its relevance to clinical practice for Fellows and Members. All papers are subject to peer review and our turnaround time for a decision averages only eight weeks.

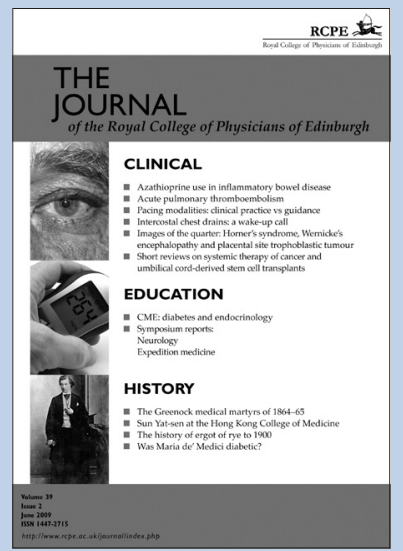

We would be pleased to consider submissions based on original clinical research, including pilot studies. The JRCPE is a particularly good forum for research performed by junior doctors under consultant supervision. We would also consider clinical audits where the 'loop has been closed' and a demonstrable clinical benefit has resulted.

For further information about submissions, please visit http://www.rcpe.ac.uk/policy-standards/jrcpeinformation-contributors or e-mail editorial@rcpe.ac.uk.Thank you for your interest in the College's journal.

The Editorial Team,

The Journal of the Royal College of Physicians of Edinburgh 